\title{
Pesquisa-ação Sobre Uso de Tecnologia da Informação no Ensino de Pessoas Surdas
}

\author{
Enyo J. T. Gonçalves ${ }^{1}$, Anilson Pimenta ${ }^{2}$ \\ ${ }^{1}$ Universidade Federal do Ceará (UFC) - Quixadá - CE - Brasil \\ ${ }^{2}$ Universidade Aberta do Brasil (UAB) \\ enyo@ufc.br, anilsonpimental@gmail.com
}

\begin{abstract}
The history of the deaf community has been accumulating achievements for centuries. Nowadays their rights to education in Brazil are guaranteed by laws and decrees, including regular education. However, the reality of this scenario often indicates to the unpreparedness of the people directly or indirectly related to the teaching of the deaf, as well as the lack of something essential: the mechanisms of Information Tecnology available to their learning. This work addresses the perceptions of deaf students and related teachers about the use of computer tools used in Primary School Education Center Mauriti, trying to identify the more they can interact in the process and use for learning. The results were analyzed and compared to references by various authors in order to enrich the discussion, in order to make allowances for prove or disprove the hypothesis initially lifted. Additionally, training was offered to those involved in research with the aim of promoting an update of the data in relation to resources that can be used for deaf students.
\end{abstract}

Resumo. A história da comunidade surda vem acumulando conquistas durante séculos. Atualmente seus direitos à educação no Brasil são garantidos por leis e decretos, inclusive no ensino regular. No entanto, a realidade deste cenário muitas vezes aponta para o despreparo das pessoas ligadas direta ou indiretamente ao ensino dos surdos, como também o desconhecimento de algo indispensável: os mecanismos de tecnologia da informação disponíveis ao aprendizado dos mesmos. Este trabalho aborda a percepção do aluno surdo e de seus professores em relação ao uso de recursos de tecnologia da informação utilizados na Escola de Ensino Fundamental Centro Educacional de Mauriti. Os resultados foram analisados e confrontados com referências de diversos autores de modo a enriquecer o debate, de modo a dar subsídios para comprovar ou refutar a hipótese inicialmente levantada. De forma complementar, uma capacitação foi oferecida aos envolvidos na pesquisa com o intuito de promover uma atualização dos mesmos em relação aos recursos que podem ser utilizados para os alunos surdos.

\section{Introdução}

A comunidade surda vem conquistando uma série de direitos no contexto da educação brasileira. A lei 10.436 reconhece a legitimidade da Língua Brasileira de Sinais LIBRAS 
e essa lei foi uma conquista da luta pelos direitos dos surdos em espaços de cidadania como a escola, sociedade e igreja. (SKLIAR, 1997).

Os recursos atuais da tecnologia, a multimídia, a internet, a telemática, trazem novas formas de ler, de escrever, e, portanto, de pensar e agir. O simples uso de um editor de textos mostra como alguém pode registrar seu pensamento de forma distinta daquela do texto manuscrito, provocando no indivíduo uma forma diferente de ler e interpretar o que escreve, forma esta que se associa, ora como causa, ora como consequência, a um pensar diferente (FRÓES, 1994, p. 18).

Muitos recursos de Tecnologia da Informação colaboram de forma significativa com o aprendizado dos alunos surdos, possibilitando uma visão lúdica do aprender. No entanto o uso destes recursos dentro da escola como ferramenta inclusiva nem sempre ocorre a contento, sobretudo em regiões distantes dos grandes centros. Assim sendo, é necessária uma análise para identificar atual cenário de uso de recursos de Tecnologia da Informação em determinada região. Os resultados podem ser utilizados para identificar deficiências que precisam ser trabalhadas e capacitações podem ser planejadas para suprir as deficiências.

Este trabalho pretende enriquecer o debate sobre o uso de recursos de Tecnologia da Informação no ensino de pessoas surdas através pesquisa qualitativa, seguida de ação relacionada com alunos surdos do centro educacional de Mauriti-Ce e seus professores. Necessidades identificadas através da análise dos questionários foram trabalhadas durante capacitação oferecida aos integrantes do universo da pesquisa.

O trabalho encontra-se dividido da seguinte forma: na seção 2 a metodologia utilizada é apresentada; na seção 3 o referencial teórico é explorado; na seção 4 os resultados alcançados e discussão são descritos; a seção 5 apresenta a capacitação realizada; e, por fim, as conclusões e trabalhos futuros são apresentados na seção 6 .

\section{Metodologia}

A presente pesquisa é caracterizada como uma pesquisa-ação, exploratória e descritiva com abordagem qualitativa e não experimental, visto a necessidade de obtenção de maiores conhecimentos acerca do tema e evidência de novas fontes de informação.

Esta estratégia associa a ação com a atividade da pesquisa e favorece a identificação das demandas dos próprios participantes do grupo, por meio do emprego da abordagem exploratória. Na pesquisa-ação os participantes possuem a possibilidade de gerar informações e utilizá-las. São dados que orientam as ações e as decisões que são tomadas em conjunto com os pesquisadores (THIOLLENT, 2002).

A pesquisa foi realizada no município de Mauriti, Ceará, mais especificamente na escola de ensino fundamental Centro Educacional de Mauriti (CEM), no período de 12 de março de 2013 a 22 de abril de 2013. E o universo da pesquisa é composto pelos professores do CEM que participam do ensino dos alunos surdos e pelos alunos surdos do CEM. Sendo contabilizada a participação de cinco professores e onze alunos, totalizando dezesseis envolvidos na pesquisa.

Inicialmente foi formulada a seguinte hipótese: $O$ uso de tecnologia da informação no ensino de surdos colabora significativamente para o aprendizado dos mesmos, porém muitas vezes não é utilizada a contento em nossas escolas. A partir desta hipótese foi desenvolvido um estudo de caso como método de procedimento. 
O questionário foi utilizado como instrumento qualitativo, sendo que um questionário específico foi criado para os professores que lecionam aos surdos (Disponível em: https://www.dropbox.com/s/tvkwi9u1m3s7q3c/Question\%C3\%A1rio $\% 20$ Professores.pdf) e outro questionário foi criado para os alunos surdos (Disponível em: https://www.dropbox.com/s/q4baww222cu2673/Question\%C3\%A1rio\%20Alunos .pdf). Vale ressaltar que a aplicação do questionário aos alunos surdos contou com a colaboração da tradutora de libras do Centro Educacional de Mauriti.

Para fins de análise e apresentação dos dados, optamos pela análise temática fundamentada por Minayo (2012) que consiste em descobrir os núcleos de sentido que compõem uma comunicação. Na pesquisa qualitativa, a análise temática se encaminha para a presença de determinados temas ligados a uma afirmação sobre determinado assunto, podendo ser representado através de uma frase, um parágrafo ou um resumo.

Finalmente uma capacitação direcionada a mitigar as necessidades identificadas nos questionários foi desenvolvida de modo a auxiliar os professores a utilizar as ferramentas em sala de aula.

\section{Referencial Teórico}

Nesta seção o cenário da escola atual e os deficientes auditivos é apresentado através da evolução histórica e algumas leis, e em seguida a importância da tecnologia da informação no ensino de surdos é desvelada.

\subsection{A Escola Atual e os Deficientes Auditivos}

O século XVIII é tido como um marco significativo no ensino de surdos em virtude da disseminação das escolas para surdos, conforme destacado por Sacks (1998, p, 34):

Esse período que agora parece uma espécie de época áurea na história dos Surdos testemunhou a rápida criação de escolas para Surdos, de um modo geral dirigido por professores Surdos, em todo o mundo civilizado, a saída dos Surdos da negligência e da obscuridade, sua emancipação e cidadania (SACKS, 1998, p.34).

Deste período até os dias de hoje houve muitas mudanças, tanto na quantidade de pessoas surdas quanto na quantidade de surdos na escola. O Censo de 2007 do IBGE revelou uma população de 183,9 milhões de habitantes no Brasil, dos quais 5,7 milhões apresentam algum tipo de problema auditivo (IBGE, 2007). Segundo o MEC, apenas 35.582 estão estudando, isto é, só $1 \%$ da população de Surdos brasileiros está matriculada na rede de ensino.

No final do século passado ao início deste, muitos estudiosos colocaram em suas teorias posicionamentos favoráveis à educação de surdos na escola normal. Diante disso, Mattos (2001) citado por Pereira e Marostega (2002), afirma:

No contexto dessas dificuldades encontradas pelos surdos, considera relevante questionar como os surdos se encontram "incluídos" nas salas de aula no ensino regular. Quase sempre, a prática nos mostra que esses alunos encontram sérias dificuldades de aprendizagem, alterações comportamentais, em abandono num canto da sala de aula, ou em tantas outras situações de dificuldades (MATTOS, 2001 apud PEREIRA; MAROSTEGA, 2002, p. 16).

Neste contexto, algumas leis brasileiras contribuíram bastante para a inversão desta realidade. A Lei 8069/90 (Estatuto da Criança e do Adolescente) em seu artigo 54 
item III afirma que é dever do Estado assegurar à criança e ao adolescente atendimento educacional especializado aos portadores de deficiência, preferencialmente na rede regular de ensino. A Lei № 9394/96 (Lei de Diretrizes e Bases) também é de extrema importância neste contexto ao caracterizar em seu artigo 58 a educação especial como sendo oferecida na rede regular de ensino e estabelecer serviços necessários na escola regular para atender portadores de necessidades especiais.

\subsection{Importância da Tecnologia da Informação no Ensino de Surdos}

A tecnologia vem adquirindo grande importância não só no nosso dia a dia, mas também no meio educacional. Vivemos em um ambiente tecnológico e, assim, a informática é um elemento muito importante na inclusão digital da nossa sociedade.

Segundo Salles (2004), recomenda-se que a educação dos surdos seja efetivada em língua de sinais, independentemente dos espaços em que o processo se desenvolva. Assim, paralelamente às disciplinas curriculares, faz-se necessária a utilização de materiais e métodos específicos no atendimento às necessidades educacionais do surdo.

Neste contexto, um conjunto de softwares como Rybená, ProfDeaf e o Dicionário de Libras tem importante papel neste sentido, facilitando o estudo e a comunicação entre os alunos através do computador.

Assim sendo, ferramentas que possibilitem a comunicação e relacionamento entre alunos surdos e alunos sem deficiência auditiva são totalmente válidas como forma de integra-los. Com isso, o uso de redes sociais pelos alunos com surdez pode auxiliar esta integração como citado por Castells (1999) que diz que as comunidades virtuais oferecem um contexto novo e impressionante, no qual pensar sobre a identidade humana na era da internet.

A vantagem da rede é que ela permite a criação de laços fracos com desconhecidos, num modelo igualitário de interação, no qual as características sociais são menos influentes na estruturação, ou mesmo no bloqueio, da comunicação. Os laços fracos facilitam a ligação de pessoas com diversas características sociais, expandindo assim a sociabilidade para além dos limites socialmente definidos do autoconhecimento. De fato, a comunicação on-line incentiva discussões desinibidas, permitindo assim, a sinceridade. (Castells, 1999)

\section{Resultados e Discussão}

Com base na metodologia de Minayo, a análise segue as seguintes temáticas: i) Dificuldades na utilização de tecnologias relacionadas à educação, ii) Caracterização do cenário atual, iii) Impacto da tecnologia utilizada e iv) Iniciativas para melhoria do ensino. Juntamente aos discursos, será apresentada a discussão e quando possível, a inserção de referencial teórico para enriquecer o debate.

\subsection{Dificuldades na utilização de tecnologias relacionadas à educação}

A primeira abordagem do questionário busca identificar se os envolvidos se consideram preparados para utilizar os recursos de Tecnologia da Informação disponíveis em sua escola. No relato dos professores nota-se dois grupos, onde o primeiro grupo é formado pelos que afirmam não ter conhecimento suficiente das tecnologias e o segundo grupo é 
formado por professores que afirmam ser capazes de utilizar a tecnologia de forma satisfatória. O discurso de um professor de cada grupo é apresentado a seguir:

"Ainda não conheço com profundidade as tecnologias relacionadas com a educação. Um dos fatores que me levaram a não conhecer foi à falta de tempo" (Professor 1).

"Considero-me apto a utilizar porque busco conhecer estes meios e utilizá-los também. Tenho graduação em letras e estou cursando Informática pele UAB, porque acredito que a tecnologia pode transformar a educação" (Professor 4).

Paralelamente, as respostas dos Alunos apontam para a diversidade de realidades, tendo três situações: alunos que não tem dificuldade, alunos que tiveram dificuldade no inicio e conseguiram superar as deficiências e outro grupo que já tinha habilidades prévias em informática e que não tem dificuldade. Os discursos apresentados a seguir mostram esta realidade:

"No inicio, foi difícil por não entender os comandos em português no laboratório de informática, com muito treino e o intérprete eu consegui assimilar e hoje estou trabalhando como aprendiz na área de informática" (Aluno 11).

"Tenho dificuldade porque estudei nove anos em sala sem interprete e não tinha computador onde morava” (Aluno 3).

"Já conhecia informática e computador e não senti dificuldades em utilizar os recursos disponíveis" (Aluno 10).

COOMBS (1976) colabora com esta discussão citando que os professores do ensino regular não têm sido preparados para a tarefa de lidar com recursos de Tecnologia da Informação em sala de aula.

Além disto, as escolas tem se mostrado desinteressadas nas suas reestruturações e adaptações para trazer ao aluno surdo um meio satisfatório para seu aprendizado. Conforme Spenassato (2009), a maioria das escolas não apresenta um quadro de inclusão de alunos com necessidades educacionais especiais, dentre esses, os surdos.

\subsection{Caracterização do cenário atual}

Foi analisada a inclusão digital dos surdos, se as tecnologias podem agregar mais ao ensino e quais, como e com que frequência as ferramentas tecnológicas são utilizadas.

Alunos surdos e professores afirmaram que na sala de aula, junto com os alunos ouvintes, não existem recursos ou ferramentas tecnológicas alguma. $\mathrm{O}$ interprete é o único recurso utilizado em sala de aula para os surdos, sem envolver recursos computacionais para tal tarefa. Porém, em paralelo às atividades regulares, eles frequentam o laboratório de informática, através do projeto JOVEM.COM durante o ano letivo, onde afirmam conseguir assimilar todos os conteúdos, usando aplicativos, internet, programas educativos e até se comunicando por LIBRAS através de webcams nas redes sociais. O projeto JOVEM.COM tem o objetivo de promover a inclusão social de adolescentes e jovens de 15 a 29 anos a partir da inclusão digital.

Declaram ainda que a tecnologia é grande aliada no processo de aprendizagem, sobretudo o computador e vídeos, onde conseguem assimilar melhor o conteúdo, 
trazendo mais conhecimentos. Os discursos a seguir ilustram a realidade explicitada pelo universo da pesquisa.

"Trabalho de forma a incluir nos meios tecnológicos que a escola oferece, como aula de computação, vídeos. A escola oferece também um intérprete” (Professor 2).

"Os alunos com deficiência auditiva estudam em uma sala junto com alunos ouvintes. Os professores trabalham junto com uma intérprete para que eles recebam acompanhamento igual aos outros. Eles também frequentam as aulas de informática no laboratório e conseguem assimilar todos os conteúdos, usam os aplicativos, internet, programas educativos e até se comunicam por redes sociais” (Professor 4).

"A escola trabalha a inclusão dos alunos surdos através de cursos de informática, palestra e filmes no "Data Show". Com a participação da intérprete de libras" (Professor 5).

"O uso do computador é importante porque facilita as pesquisas e a interação com o mundo. É bem mais fácil a comunicação pela internet, através de vídeos é mais fácil" (Aluno 2).

"A dificuldade é não ter internet em casa, mas no CEM (Centro Educacional de Mauriti) encontramos e fazemos uso" (Aluno 4).

"A internet é grande aliada da aprendizagem. Conhecemos muitas pessoas e conhecimentos" (Aluno 9).

É possível identificar nas respostas acima que há consenso entre professores e alunos entrevistados em relação a importância do uso do computador para pluralizar a forma de ensino aos alunos surdos e possibilitar contato com outras realidades.

Segundo Arcoverde e Gianini (2000),

No ambiente telemático os surdos têm tido a oportunidade de dialogar sem opressão das diferenças e compreender quais são os projetos comuns para além da diferença. Este também tem sido um espaço de denúncia do fracasso escolar e da deficiência na educação dos surdos. (ARCOVERDE; GIANINI, 2000, p.4).

A autora destaca e indica, assim, o uso da informática como ferramenta pedagógica e atividade no processo de comunicação escrita e interação social das pessoas envolvidas. Realça a importância de construir meios alternativos e espaços de desenvolvimento cognitivo e sócio afetivo.

No terceiro item dos questionários os alunos foram questionados se existe preconceito sobre o uso de tecnologia e se existe incentivo para o uso dos meios tecnológicos existentes na escola. Já os professores foram questionados acerca da forma como essas ferramentas colaboram (ou poderiam colaborar) com o ensino-aprendizagem dos surdos em suas aulas.

Os surdos afirmaram não ter aversão às tecnologias. Pelo contrário, fazem questão de estar presente nas palestras onde são apresentados vídeos, afirmando ainda que são sempre incentivados praticar nos computadores do laboratório da escola, onde segundo a professora do laboratório eles conseguem fazer tudo que lhes são solicitados durante o uso do computador. De forma complementar, os alunos citam o uso de Datashow de modo a viabilizar a apresentação de palestras e vídeos. O discurso dos entrevistados em relação a este tema são citados a seguir: 
"Eles usam os softwares normais, sem diferença, pois conseguem entender tudo e fazer tudo que é solicitado, seja uma pesquisa, um texto com tabela ou imagem, planilha eletrônica ou apresentação em slide" (Professor 4).

"Nas salas, os alunos surdos não utilizam estes programas educativos. Seria uma oportunidade maravilhosa para os surdos esse método de ensino voltado para novos programas" (Professor 5).

"Não tenho aversão às tecnologias, pois sempre estamos participando de atividades que facilita a compreensão através de palestras e vídeos” (Aluno 2).

"O professor de informática nos auxilia nessa prática tecnológica, através do projeto JOVEM.COM” (Aluno 4).

"Somos muito incentivados à praticar as tecnologias, destaco a professora de português, ciências e matemática" (Aluno 9).

Na direção desta discussão, Stumpf (2000, p. 7) mostra-nos uma relevante observação:

\footnotetext{
Seja aproveitando as possibilidades de pesquisa, compras, transação bancárias (sic), seja através de correio eletrônico ou das salas de bate-papo, os surdos brasileiros estão aproveitando a internet mais do que ninguém! Todo e qualquer surdo que entre em contato com a internet vira fã de carteirinha. (STUMPF, 2000, p. 7).
}

No quarto item do questionário, professores e alunos são indagados sobre qual movimento a escola tem desenvolvido para melhorar o convívio de alunos deficientes auditivos, alunos sem deficiência e família (inclusão social) e como as ferramentas tecnológicas poderiam auxiliar neste contexto.

Conforme responderam, não existe preconceito ao se integrarem nos meios tecnológicos, e boa parte dos professore incentivam ao uso de computador, sobretudo o do laboratório de informática e que os inserem no projeto JOVEM.COM do Centro educacional de Mauriti. Afirmaram que o relacionamento na escola é apenas com alunos ouvintes, professores e direção. Os trechos de discurso destacados são apresentados abaixo:

"A ação é justamente trabalhar com eles (surdos) junto com os outros alunos (sem deficiência) e as ferramentas computacionais auxiliam por conta da maneira lúdica de ensinar com a utilização do computador e internet" (Professor 4).

"A escola tem contribuído bastante nesta inclusão social dos alunos surdos com os ouvintes. Nas salas de aula, palestras, filmes, jogos e eventos. O uso de software educativo específico iria contribuir bastante neste contexto.” (Professor 5).

“...seria muito bom se os professores e colegas aprendessem libras pra facilitar a comunicação.” (Aluno 11).

Se softwares fossem utilizados entre alunos deficientes e não deficientes e os professores, a comunicação em sala de aula poderia ser melhorada, inclusive ferramentas lúdicas poderiam ser utilizadas neste processo como ferramenta integradora. 


\title{
4.3 Impacto da tecnologia utilizada
}

$\mathrm{Na}$ quinta pergunta foi pedido aos professores envolvidos que fizesse uma análise de melhorias comparando o aprendizado sobre o antes e o depois do uso das ferramentas tecnológicas.

Conforme respostas dos participantes, antes a maioria dos surdos não tinha um conhecimento muito aprofundado destas ferramentas tecnológicas, eram inibidos, mais lentos e interagiam pouco com outros colegas.

"Antes eram inibidos (os alunos surdos), mais lentos e interagiam pouco com os outros alunos; Depois: Ficaram mais extrovertidos, melhoraram a aprendizagem e passaram se comunicar de forma mais alegre e contínua com os outros colegas e professores" (Professor 4).

"Antes muitos dos nossos surdos não tinham um conhecimento muito aprofundado destas ferramentas. Agora depois do uso do laboratório, os alunos desenvolveram bastante seu ato de leitura, escrita e outras formas de aprendizagem" (Professor 5).

As tecnologias abriram portas e tem considerável crescimento devido à necessidade de melhorar o processo de ensino aprendizagem. Uma dessas conquistas é o benefício da comunicação. Podemos identificar os seus benefícios na citação abaixo:

\begin{abstract}
Através da internet, é possível ignorar o espaço físico, conhecer e conversar com pessoas sem sair de casa, digitar textos com imagens em movimento, ver fotos, desenhos, ao mesmo tempo em que podemos assistir vídeos, fazer compras, estreitar relacionamentos em comunidades virtuais, participar de bate-papos (chats), consultar o extrato bancário, pagar contas, ler as últimas notícias em tempo real, enfim, estudo e lazer se confundem no cyber espaço. (ROCHA 2008, p. 01)
\end{abstract}

\subsection{Iniciativas para melhoria do ensino}

Por fim foram feitos os seguintes questionamentos aos professores: Como sua escola e você poderiam melhorar o ensino dos alunos surdos e quais ações poderiam ser tomadas com o uso das tecnologias, promovendo a quebra de paradigmas na relação aluno/professor nesta escola?

Um ponto importante a destacar nos discursos é que, segundo os entrevistados, todos os professores deveriam planejar aulas mais interativas e dinâmicas, sobretudo com auxilio de tecnologia para facilitar a transmissão de conteúdo, levando ao aluno surdo uma aprendizagem mais satisfatória. Continuaram afirmando que a relação aluno/professor tem sido muito boa, onde a afetividade é mais evidenciada por se tratarem de alunos especiais. Os discursos mais relevantes aparecem a seguir:

"Criando um espaço, onde os deficientes auditivos pudessem estar mais presentes neste espaço educacional. Seria bom que a escola fizesse parceria com órgão competente no sentido de promover capacitações aos professores e melhorar a escola tecnologicamente" (Professor 1).

"Em primeiro lugar, que os professores participem de cursos de modo a haver qualificação para utilizar softwares e outros recursos tecnológicos em sala de aula. Em segundo lugar, que todos os professores planejem aulas interativas e dinâmicas para facilitar a transmissão do conteúdo." (Professor 4). 
Neste contexto, Belloni (2003) afirma que:

\begin{abstract}
Para fazer frente a esta nova situação, o professor terá necessidade muito acentuada de atualização constante, tanto em sua disciplina específica, quanto em relação às metodologias de ensino e novas tecnologias. (BELLONI, 2003, p. 83)
\end{abstract}

\title{
5. Capacitação
}

A ação deste trabalho envolve uma capacitação direcionada às necessidades dos professores, intérpretes e instrutores do laboratório de informática. Os resultados da análise qualitativa apresentados na seção anterior serviram como indicador para $o$ planejamento da capacitação que contou também com reunião realizada para definição colaborativa da agenda da capacitação.

O treinamento foi realizado no período de 22 a 26 de maio de 2013 com carga horária de 36 horas, tendo a finalidade de contribuir como a melhoria do ensino dos surdos daquela escola através da viabilização do uso das TICs no processo de ensinoaprendizagem, almejando melhorar a compreensão e o entendimento destes alunos nos conteúdos abordados.

A capacitação foi realizada de modo a apresentar softwares, sites, portais, redes sociais, materiais em DVD (filmes, documentários e desenhos) direcionados à comunidade surda. Também foram analisadas campanhas de nível nacional voltado aos surdos. Dentre estes recursos podemos citar: Dicionário Libras (disponível em www.dicionariolibras.com.br/), ProDeaf (disponível em www.prodeaf.net), Acessibilidade Brasil (disponível em www.acessobrasil.org.br/libras/), Blog Daniane Pereira (danianepereira.blogspot.com.br), Surdosol (disponível em www.surdosol.com.br), Portal do Surdo (disponível em www.portaldosurdo.com) entre outros.

Os softwares foram apresentados em um primeiro momento na forma teórica através de slides com definições, objetivos e imagens. Logo após, foram abertos os links desses softwares para demonstração de uso e oficinas, onde todos os envolvidos através utilizaram estes recursos.

\section{Conclusões e Trabalhos Futuros}

Através desta pesquisa, verificou-se que os professores e alunos integrantes do universo da pesquisa utilizam tecnologia no contexto educacional, no entanto o uso ainda não acontece a contento, devido a necessidade de capacitações. Foi constatado também que o computador vem sendo utilizado pelos alunos entrevistados como meio de inclusão social e de modo a potencializar seu aprendizado.

Com esse confronto de ideias podemos comprovar que a hipótese levantada inicialmente (O USO DE TECNOLOGIA DA INFORMAÇÃO NO ENSINO DE SURDOS COLABORA SIGNIFICATIVAMENTE PARA O APRENDIZADO DOS MESMOS, PORÉM MUITAS VEZES NÃO É UTILIZADA A CONTENTO EM NOSSAS ESCOLAS) está correta. Possivelmente a realidade encontrada é compartilhada por vários municípios brasileiros, sobretudo os menos desenvolvidos. Há de se destacar que o cenário vem melhorando significativamente nos últimos anos. 
Um trabalho que deve ser desenvolvido é a análise das mudanças alcançadas pela capacitação, análise das necessidades atuais dos professores e realização de novas capacitações. Outra possibilidade de continuidade deste trabalho é a realização de capacitação para os alunos com intermédio do tradutor de libras.

\section{Referencias}

ARCOVERDE, R.D.L; GIANINI, E. - Internet e surdos: possibilidades infinitas de comunicação. Disponível em: <www2.insoft.br/ scie/1999/RossanaDLArcoverdeInternetESurdos.html>. Acesso em 15/06/2013.

BELLONI, Maria Luiza. Educação à distância. Campinas, São Paulo: Autores Associados, 2003.

CASTELLS, Manuel. Tradução de Roseneide Venâncio Majer. A sociedade em rede. A era da informação: economia, sociedade e cultura, v. 1. São Paulo: Paz e Terra, 1999.

COOMBS, Philip. A crise mundial da educação. São Paulo: Perspectiva, 1976. das propostas didático-metodológicas desenvolvidas por professores de matemática.

FRÓES, J. A tecnologia na vida cotidiana: - importância e evolução sócio-histórica Rio de Janeiro, 1994.

IBGE. Contagem da População 2007. IBGE, 2007. Disponível em: /<http://www.ibge.gov.br/home/estatistica/populacao/contagem2007/contagem.pdf

MINAYO, Maria Cecília de Souza. O desafio do conhecimento: pesquisa qualitativa em saúde. 12. ed. São Paulo: Hucitec, 2012

ROCHA, Sinara Socorro Duarte. O uso do computador na Educação: a informática educativa. Revista Espaço Acadêmico. No 85, ano 08, Junho de 2008. Disponível em http://www.espacoacademico.com.br/085/85rocha.htm

SACKS, O. W. Vendo vozes: uma jornada pelo mundo dos surdos. Rio de Janeiro: Imago, 1998.

SALLES, H. M. Ensino de língua portuguesa para surdos: caminhos para a prática pedagógica. Ministério da Educação. Secretaria de Educação Especial; Programa Nacional de Apoio à Educação de Surdos. v. 1 Brasília: MEC/SEESP, 2004.

SPENASSATO, Débora. Inclusão de alunos surdos no ensino regular: investigação das propostas didático-metodológicas desenvolvidas por professores de matemática no ensino médio da EENAV. Disponível em: http://www.projetos.unijui.edu.br/matematica/cd_egem/fscommand/CC/CC_60.pdf.

STUMPF, M. R. Línguas de Sinais: escrita dos surdos na internet. Porto Alegre: Escola Especial Concórdia - ULBRA, 2000. Disponível em : http://lsm.dei.uc.pt/ribie/docfiles/txt200372012213L\%C3\%ADngua\%20de\%20sinais .pdf.

SKLIAR, Carlos, Educação \& exclusão: abordagens sócio-antropológicas em educação especial. Porto Alegre: Editora Mediação,1997

THIOLLENT, Michel. Metodologia da pesquisa-ação. 11 ${ }^{\mathrm{a}}$ ed. São Paulo: Cortez, 2002. 